\title{
An optimised search strategy is necessary to ensure a thorough search of the literature
}

\author{
Jiangfeng $\mathrm{Wu}^{1}{ }^{\wedge}$, Peipei $\mathrm{Yu}^{1}$, Jingwen Zhang ${ }^{1}$, Qingqing Fang ${ }^{2}$ \\ ${ }^{1}$ Department of Ultrasound, The Affiliated Dongyang Hospital of Wenzhou Medical University, Dongyang, China; ${ }^{2}$ Department of Ultrasound, \\ Tianxiang East Hospital, Yiwu, China
}

Correspondence to: Jiangfeng Wu. Department of Ultrasound, The Affiliated Dongyang Hospital of Wenzhou Medical University, Dongyang 322100, China. Email: wjfhospital@163.com.

Comment on: Niu Z, Xiao M, Ma L, Qin J, Li W, Zhang J, Zhu Q, Jiang Y. The value of contrast-enhanced ultrasound enhancement patterns for the diagnosis of sentinel lymph node status in breast cancer: systematic review and meta-analysis. Quant Imaging Med Surg 2022;12:936-48.

Submitted Dec 15, 2021. Accepted for publication Jan 05, 2022.

doi: 10.21037/qims-21-1207

View this article at: https://dx.doi.org/10.21037/qims-21-1207

We read with interest the article by Niu et al. (1) entitled "The value of contrast-enhanced ultrasound enhancement patterns for the diagnosis of sentinel lymph node status in breast cancer: systematic review and meta-analysis". Niu et al. (1) demonstrated that a homogeneous or uniform enhancement pattern suggested a benign lymph node, and a heterogeneous, no pattern, or weak enhancement pattern suggested a node is malignant, with a high sensitivity of $96.0 \%$ and moderate specificity of $80.7 \%$. After a careful reading of this paper by Niu et al. (1), we would like to raise two points that should be considered in order to enhance the validity of the conclusion.

Firstly, Niu et al. (1) performed a systematic search for relevant studies through several electronic databases. However, after reviewing relevant articles, we found that an additional study by Agliata et al. (2) assessing the value of contrast-enhanced ultrasound (CEUS) in the evaluation of sentinel lymph node (SLN) status in patients with breast cancer meets the eligibility criteria and should be enrolled in this meta-analysis. The incomplete research results may lead to possibility of selection bias, affecting the generalizability of the conclusion. An optimized search strategy is the key to ensure a comprehensive search for relevant articles.

Secondly, publication bias is inherent to the publication process, where larger studies or studies with positive results are often given priority for publications. For the evaluation of heterogeneity, meta-regression, and publication bias section, Niu et al. (1) described that the assessment of publication bias was carried out with Egger's linear regression. However, this study is a systematic review and meta-analysis of diagnostic test accuracy studies. We believe that the Deeks' funnel plot asymmetry test, which is a specific application developed for the assessment of publication bias of a meta-analysis of diagnostic accuracy studies (3-5), is more preferred than Egger's linear regression used by Niu et al. (1).

In short, Niu et al. (1) described issues with regard to the value of CEUS enhancement patterns for the diagnosis of SLN status in breast cancer. However, the conclusion of this study should be interpreted with caution because of the concerns stated above.

\section{Acknowledgments}

Funding: None.

$\wedge$ ORCID: 0000-0002-5036-799X. 


\section{Footnote}

Provenance and Peer Review: This article was a standard submission to the journal. The article did not undergo external peer review.

Conflicts of Interest: All authors have completed the ICMJE uniform disclosure form (available at https://qims. amegroups.com/article/view/10.21037/qims-21-1207/coif). The authors have no conflicts of interest to declare.

Ethical Statement: The authors are accountable for all aspects of the work in ensuring that questions related to the accuracy or integrity of any part of the work are appropriately investigated and resolved.

Open Access Statement: This is an Open Access article distributed in accordance with the Creative Commons Attribution-NonCommercial-NoDerivs 4.0 International License (CC BY-NC-ND 4.0), which permits the noncommercial replication and distribution of the article with the strict proviso that no changes or edits are made and the original work is properly cited (including links to both the formal publication through the relevant DOI and the license). See: https://creativecommons.org/licenses/by-nc-nd/4.0/.

Cite this article as: Wu J, Yu P, Zhang J, Fang Q. An optimised search strategy is necessary to ensure a thorough search of the literature. Quant Imaging Med Surg 2022;12(4):2616-2617. doi: 10.21037/qims-21-1207

\section{References}

1. Niu Z, Xiao M, Ma L, Qin J, Li W, Zhang J, Zhu Q, Jiang $Y$. The value of contrast-enhanced ultrasound enhancement patterns for the diagnosis of sentinel lymph node status in breast cancer: systematic review and meta-analysis. Quant Imaging Med Surg 2022;12:936-48.

2. Agliata G, Valeri G, Argalia G, Tarabelli E, Giuseppetti GM. Role of Contrast-Enhanced Sonography in the Evaluation of Axillary Lymph Nodes in Breast Carcinoma: A Monocentric Study. J Ultrasound Med 2017;36:505-11.

3. Deeks JJ, Macaskill P, Irwig L. The performance of tests of publication bias and other sample size effects in systematic reviews of diagnostic test accuracy was assessed. J Clin Epidemiol 2005;58:882-93.

4. Salameh JP, Bossuyt PM, McGrath TA, Thombs BD, Hyde CJ, Macaskill P, et al. Preferred reporting items for systematic review and meta-analysis of diagnostic test accuracy studies (PRISMA-DTA): explanation, elaboration, and checklist. BMJ 2020;370:m2632.

5. Wu J, Wang $Y$, Wang $Z$. The diagnostic accuracy of ultrasound in the detection of foot and ankle fractures: a systematic review and meta-analysis. Med Ultrason 2021;23:203-12. 